\title{
CREANDO Y COMPARTIENDO CONOCIMIENTO CON HERRAMIENTAS 2.0: UNA EXPERIENCIA SOBRE LAS PRÁCTICAS DEL GRADO EN EDUCACIÓN INFANTIL EN ENTORNOS DE APRENDIZAJE COLABORATIVO
}

\author{
Raúl Santiago Campión \\ Universidad de La Rioja \\ Luis Alberto Andía Celaya \\ Profesor del I.E.S. Barañain
}

RESUMEN: El aprendizaje on-line es ya una realidad habitual en el mundo de la educación y, específicamente, en el de la educación superior. En este artículo se ofrece una experiencia real de aplicación de algunas herramientas de la web 2.0 en el contexto de la asignatura de Prácticas de Orientación Familiar y Escolar en el Grado en Educación Infantil. Se aportan los modelos de planteamiento de las diferentes actividades y la descripción de las tareas realizadas, así como los resultados sobre el grado de satisfacción de los alumnos obtenidos a través de encuestas on-line, llevando a cabo una comparación con los métodos tradicionales utilizados por la mayoría de las materias cursadas.

PALABRAS CLAVE: Educación superior, web 2.0, colaboración, papel del docente.

\section{BUILDING AND SHARING KNOWLEDGE WITH WEB 2.0 TOOLS: A CASE STUDY IN THE DEGREE OF EDUCATION THROUGH COLLABORATIVE LEARNING ENVIRONMENTS}

\footnotetext{
ABSTRACT: Online learning is nowadays an actual fact within education context an specifically in the Higher Education one. In this article we describe a real educational experience using some web 2.0 resources in the context of practical activities carried out with students of the subject "Educational Counseling: family and school". We describe the didactic model, the developed activities and resources used. We also include the obtained results and opinions
} 
by the participating students, comparing this system with the traditional one followed in most of the subjects.

KEYWORDS: Higher Education, web 2.0, collaboration, teacher's role.

Recibido: 08/06/2011

Aceptado: 19/09/2011

\section{INTRODUCCIÓN}

\section{Contexto}

Entre los objetivos planteados por el docente de la asignatura "Orientación Escolar y Familiar" y, en concreto, en el desarrollo de las actividades prácticas, se destacan los siguientes:

a) Utilizar las Tecnologías de la Información y la Comunicación (desde ahora TIC) y 2.0 como medio de recogida de información para el desarrollo de las prácticas de la asignatura.

b) Aplicar las TIC como medio de comunicación con el docente y resto de compañeras.

c) Integrar las TIC y los recursos 2.0 como medio de evaluación de actividades y tareas de las estudiantes.

d) Mejorar la planificación, el diseño y la evaluación de la memoria de trabajo del estudiante mediante la utilización de recursos de la web 2.0.

La consecución de estas metas se enmarca dentro de la adquisición de competencias que está prevista en los planes de estudios adaptados al Espacio Europeo de Educación Superior (EEES). Entre estas se destaca: saber la respuesta correcta y saber cómo se llega a ella (conocimientos); saber hacer: saber aplicar los conocimientos al trabajo (destrezas y habilidades); y, saber ser: saber mejorar constantemente y saber adaptarse con rapidez a los cambios mediante un proceso de formación y aprendizaje permanente (actitudes y valores).

Con todo ello se pretende realizar un cambio de enfoque en el proceso de enseñanza-aprendizaje. Es decir, habría que desplazar el foco de atención de lo que enseña el profesor a lo que aprende el estudiante, que pasaría a ser el centro del proceso de aprendizaje. Este cambio responde a las demandas de la sociedad actual en la que, además de los conocimientos provenientes de contenidos, se exige en el mercado profesional personas capaces de trabajar en equipo, de liderar, de promover el cambio, de comprometerse con el trabajo y de saber negociar, entre otras cuestiones (Riesco, 2008). Desde este nuevo enfoque, se da la máxima importancia al desarrollo integral de las potencialidades del alumnado, primando las intervenciones, la participación individual y grupal, el aprendizaje colaborativo, etc.

Dentro de este planteamiento, la evaluación también queda modificada, ya que se elimina la evaluación final y se opta por la evaluación continua centrada en las competencias más que en los contenidos (McDonald, Boud, Francis y Gonczi, 
2000; Gerard y Bief, 2008; Cano, 2008). La evaluación se plantea como aspecto coherente con el resto de elementos del diseño curricular, por lo que las experiencias metodológicas más frecuentes son las simulaciones, los proyectos o los PBL (Problem Based Learning o aprendizaje basado en problemas) que deben llevar a los alumnos a un proceso de autorregulación que los haga conscientes de sus puntos fuertes y de aquellos que deben corregir, de manera que se establezca un proceso de aprendizaje continuo (Long Life Learning) (Boekaerts, Pintrich y Zeidener, 2000; De la Fuente, Justicia, 2003). Se combina la autoevaluación con la evaluación externa del supervisor, o de otros alumnos. Además, se promueven resoluciones en diversos contextos a través de la del planteamiento de casos o problemas. La competencia presenta un comportamiento dinámico y su análisis debe ir provisto de una revisión constante y de la capacidad de aprender a aprender.

Todo ello implica que el rol del docente sufre una profunda transformación que lo convierte más que en un dispensador de conocimiento en un facilitador de materiales y líneas de trabajo (Rodríguez Diéguez, 2004).

\section{Experiencias de la web 2.0 en la enseñanza universitaria}

En España son ya numerosas las descripciones de experiencias basadas en el contexto de los recursos 2.0 en la enseñanza universitaria (Trujillo e Hinojo, 2010; Echazarreta, Prados, Poch, y Soler, 2009; Moral y Villalustre, 2008). Incluso, muchas de las universidades españolas están integrando estos recursos y disponen casi en su totalidad de una web para el uso del alumnado.

Han proliferado, además, los cursos virtuales que se combinan con otros de tipo presencial. Destacan, en este terreno, el "Proyecto Aula a Distancia y Abierta de la Comunidad de Madrid", que integra a seis universidades públicas. También se debe citar el programa de la Junta de Andalucía "Universidad Digital", que tiene como objetivo facilitar a los estudiantes el acceso a servicios e infraestructuras de comunicación e información mediante tecnologías wi-fi, facilitándoles la compra de ordenadores portátiles.

Otra tendencia que se observa actualmente es el paso de la publicación de las aulas virtuales en plataformas comerciales como Blackboard a plataformas de código abierto como Moodle.

Para comprender tales afirmaciones se considera importante definir, aunque sea de modo muy breve, los rasgos fundamentales de la web 2.0 (Santiago y Navaridas, en prensa):

"La web 2.0 aúna tres elementos técnicos, fundamentalmente: las capacidades del software cliente-servidor, la sindicación de contenidos y los protocolos de red. Además, los navegadores que se utilicen deberán contar con los adecuados plug-ins o extensiones para 'soportar' los diversos tipos de formatos y características técnicas que se incorporen (por ejemplo, flash player para youtube o java) y que posibiliten la interacción de los usuarios. Los sitios web 2.0 suelen proporcionar también medios para la creación de contenidos, sistemas de almacenamiento y difusión de los mismos, que no son posibles en los entornos web 1.0". 


\section{DESCRIPCIÓN DE LA EXPERIENCIA}

\section{Herramientas y planteamiento de la actividad}

Esta experiencia se inserta en la asignatura de Prácticas de Orientación Familiar y Escolar en el Grado en Educación Infantil, participando un total de 68 alumnas.

Se seleccionaron, a priori, una serie de herramientas 2.0 que resultaran apropiadas para poner en práctica lo referido anteriormente y conseguir los objetivos reseñados al comienzo. Se detallan, a continuación:

- PodCast: consiste en la creación de archivos de sonido (en mp3 o en ogg), que admite suscribirse mediante un archivo RSS (Rich Site Summary), que permite su descarga. Esto hace que el usuario pueda escucharlo cuando lo desee, habitualmente en un reproductor portátil. Este recurso se ha utilizado como medio de descripción del contenido y rúbrica de cada una de las actividades prácticas.

- Wiki: se trata de un sitio en un servidor web que permite a los usuarios crear y editar contenido en páginas web de forma sencilla y permite el enlace entre diversas páginas. Los usuarios pueden crear y modificar un mismo texto que comparten. La wiki ha sido el recurso principal sobre el que se ha desarrollado el trabajo de los alumnos.

- Blog: se puede definir como un sitio web actualizado que recopila cronológicamente textos o artículos de uno o varios autores. Siempre aparece primero el más reciente, pero el autor conserva la libertad de dejar publicado lo que crea pertinente. Hay, por lo tanto, una clara distinción entre "consumidor" y "creador". El objetivo, con la utilización de esta herramienta, era fomentar el intercambio de opiniones sobre los diferentes recursos que los alumnos iban manejando.

- Sistemas de almacenamiento de la información, algunos en formato multimedia. Fundamentalmente presentaciones (slideshare), vídeos (youtube, vimeo) y encuestas (surveymonkey).

- Redes sociales, en concreto Facebook, que se utilizaba como sistema de difusión de la información cada vez que se producía un cambio o novedad en los descriptivos de las actividades.

En un momento inicial, se constató que el nivel previo de manejo de estas herramientas por parte del alumnado era prácticamente nulo (salvo en el caso de las redes sociales). Para subsanar este problema se dedicaron dos sesiones de formación a proporcionar los conocimientos básicos para su utilización. De manera inmediata se pudo apreciar la rapidez y fluidez en la comunicación que se obtiene con este sistema. La wiki permite una comunicación casi instantánea de ideas entre los alumnos y de estos con el profesor, contribuye al ahorro de papel y permite una mayor accesibilidad al contenido de las sesiones a través de podcast. Esto permite al alumno una preparación previa del trabajo y también un acercamiento a posteriori a los materiales. 


\section{Desarrollo de la experiencia}

Tradicionalmente, las prácticas propuestas por un docente de cualquier materia suponían un trabajo en equipo que se iba construyendo y plasmando en papel. Si un estudiante no podía asistir a la hora de prácticas implicaba la demora en la entrega, o que el alumno que había faltado no se enterara del contenido desarrollado por el resto de sus compañeros. Asimismo, la falta de un integrante del equipo suponía una desventaja con respecto al resto del aula.

Bajo el prisma del nuevo modelo, se seleccionaron y utilizaron aquellas herramientas más adecuadas:

- Por un lado, el podcast (vidcast, o podcast de video), como medio de explicación de los objetivos, actividades, proceso y sistema de evaluación. Este recurso era diseñado y creado por el profesor, y consistía en un video en el que se sincronizaban las pantallas de explicación con la voz del docente que proporcionaba más información o ponía énfasis en determinados aspectos clave de la actividad.

- Un sitio web que constituía el eje central de las actividades, con acceso a los materiales, podcast, enlaces a sitios de referencia y a las propias wikis de las estudiantes. A este sitio se podía llegar desde un enlace a partir del propio campus virtual de la Universidad de La Rioja (Blackboard)

- Blog, que se utilizó fundamentalmente como recurso de creación de conocimiento de modo colaborativo, especialmente en algunas sesiones con el gran grupo y con el objetivo de preparar las actividades: http://respuestadiversidad. blogspot.com.

- La wiki. Su nombre procede del término hawaiano que significa "rápido". Esta herramienta es de fácil acceso y sus páginas, como hemos comentado anteriormente, pueden ser editadas por varios usuarios a la vez. Un mismo texto se puede compartir, editar, borrar por cualquiera de las personas que lo comparten en cualquier momento y desde cualquier lugar. Además, la wiki permite incorporar archivos, fotografías, vídeos, etc. enriqueciendo, de este modo, el trabajo. En un primer momento, el desconocimiento de qué era una wiki supuso una gran inversión de tiempo, ya que las estudiantes tuvieron que crearla y familiarizarse con ella. Una vez que se familiarizaron con la herramienta, descubrieron que su utilización dotaba de mayor rapidez a la comunicación y que ésta había dejado de ser necesariamente presencial. Las ideas fluían de forma casi instantánea entre las estudiantes y entre éstas y profesor. Además, evitaban la pérdida o el deterioro del papel que hubieran utilizado, ya que de manera inmediata todo quedaba colgado en la wiki y si una alumna, en particular, no podía asistir a las prácticas, podía acceder a ellas desde su casa a través de la red. La wiki les permitía, además, conocer con anterioridad el contenido de la clase a la que iban a asistir. El profesor comentaba con las alumnas sus ideas, sus propuestas y proporcionaba el resultado del trabajo realizado de forma casi inmediata. En total se realizaron 12 wikis, una por cada grupo de entre 5 y 6 estudiantes. 
- Adicionalmente, las alumnas utilizaban otros recursos de la web 2.0 como medio de presentación, información o recogida de evidencias; todos ellos se incrustaban dentro de la wiki: Slideshare y Prezi, para embeber las presentaciones; Youtube y/o Vimeo, para crear o seleccionar evidencias en forma de video y audio; GoogleDocs y Scribd, para incluir documentos; Picasa, Flickr y Google, para seleccionar o almacenar imágenes; Ivoox, para crear o seleccionar materiales en formato audio (podcast).

- Surveymonkey, como recurso para la realización, diseño o interpretación de encuestas online sobre temas relacionados con las prácticas o la propia evaluación de las mismas.

\section{Contenidos de las prácticas}

Resumidos de manera casi telegráfica, el contenido de las cinco prácticas que han constituido el contenido de trabajo por parte de las alumnas. Para acceder al conjunto detallado de las mismas, se puede acceder a la URL donde se muestran de modo público: http://web.me.com/santiagoraul/practicasofye/presenta cion.html.

- Práctica 1: Objetivo general: Recordar a todos los maestros y maestras, profesores y profesoras que has tenido a lo largo de tus estudios desde que se comenzó la escolarización e imaginar las mejores cualidades de cada uno de ellos, así como las cosas que hacían bien durante las clases y que personalmente le agradaban por lo que se aprendía o lo bien que se sentía. Todo ello referido no solo a su vertiente "académica", sino también "orientadora" y "tutorial". Tareas: cuestionarios online y debate entre las componentes del grupo. Durante la clase. Seleccionar imágenes o videos de internet que resulten significativos y relevantes y apoyen o reafirmen los comentarios. Evaluación y criterios de evaluación: La realización del cuestionario como parte del material. La realización de una reflexión personal y posteriormente en grupo, teniendo en cuenta: a) El cuestionario en papel realizado, b) La encuesta online realizada c) Sus propias vivencias o experiencias.

- Práctica 2: Objetivo general: En esta actividad se trata de profundizar en el tema de la autoridad del profesor/a. Se reflexionará sobre problemas y posibles soluciones. Tareas: Antes de clase, descarga de un guión con preguntas, selección de tres noticias sobre la puesta en cuestión de la autoridad docente para aportarlas en clase. Lectura de un artículo de El País sobre el tema y del Dossier del proyecto de Ley Autoridad Docente, del Gobierno de La Rioja. Especialmente las secciones 6 a 11. En clase, debate en grupos pequeños sobre el material citado y, posteriormente, debate entre toda la clase. Después de la clase, redacción de una síntesis global de lo tratado en el debate en pequeño grupo y presentación al gran grupo. Evaluación y criterios de evaluación: la valoración de esta práctica se hará de acuerdo a la realización de una reflexión grupal sobre lo ya señalado, la entrega de las tres noticias y de un breve 
comentario sobre ellas y la calidad expresiva, terminológica, argumental y de contenido de los materiales presentados.

- Práctica 3: Objetivo general: Elaboración de un estudio de caso (documentado o ficticio) y "resolución" de otro elaborado por otras compañeras. Tareas: Antes de clase, estudio de un caso concreto para conocer la estructura, metodología y redacción de casos. Elaboración del caso, propuesta de guión y publicación en una wiki. Resolución del otro caso y publicación del resultado en la wiki. En clase: debate sobre las propuestas de resolución. Evaluación y criterios de evaluación: Se valorará la realización del estudio de caso teniendo en cuenta la originalidad del caso, el material empleado, la redacción del mismo, las preguntas elaboradas, así como la cantidad y la calidad de los datos proporcionados. En la solución del caso se atenderá a la coherencia en la descripción de los factores identificados y las posibles soluciones $y$, en general, a la riqueza expresiva y la calidad en la estructura y la redacción del contenido.

- Práctica 4: Objetivo general: Se trata de elaborar un material (producto) y de reflexionar sobre cómo se ha llegado a elaborarlo (proceso). Tareas: Antes de clase, decidir el producto en el que se quiere trabajar (adaptación curricular, material específico, proyecto de gestión y/o administración, etc.). Respuesta a una serie de preguntas sobre el proceso. En clase, finalización del trabajo, exposición y muestra del proceso seguido. Evaluación y criterios de evaluación: Esta actividad se valora con 10 puntos y se puntuará de 0 a 10 (3 el producto y 7 el proceso). Se realizará de modo colaborativo. Ambas tareas se ubicarán en la wiki como actividad 4.

- Práctica 5: Objetivo general: Se trata de elaborar un Plan de Acción Tutorial (PAT). Tareas: Antes de clase estudio de posibles núcleos de actividad sobre el que se vaya a realizar el PAT, como pueden ser acogida e integración del alumnado, organización y funcionamiento del grupo-clase, desarrollo y adaptación personal, escolar y social (enseñar a ser persona y enseñar a convivir), adquisición y mejora de los hábitos de trabajo y autocuidado (enseñar a pensar) y participación de las familias. Acceso a varios ejemplos reales. En clase, distribución en grupos pequeños y sorteo de los núcleos de actividad. Realización de una propuesta de PAT que se entrega mediante una wiki. En clase y fuera de ella, realización del trabajo donde debe figurar la siguiente información: Describir lo que para vosotros/as es el área en la que se quiere intervenir (la que os haya tocado en el sorteo), que se desarrollará para 3, 4 y 5 años. Objetivos generales. Objetivos específicos. Fases y/o temporalización. Actividades a desarrollar. Medios y/o recursos necesarios. Agentes implicados. Evaluación de la acción. Se efectuará una presentación del trabajo al resto del grupo. Evaluación y criterios de evaluación: Se valorará de acuerdo a la calidad de los materiales utilizados, las actividades propuestas y los niveles de concreción, realismo, coherencia y aplicabilidad del proyecto, los instrumentos y técnicas propuestos, los materiales adjuntos y la calidad de la exposición ante el gran grupo. Las tareas se ubicarán en la wiki. 


\section{Proceso}

El proceso de trabajo lo podemos resumir sintéticamente en cinco pasos:

a) Diseño, producción y distribución del material 2.0. Esta tarea era realizada por el docente previamente a la explicación en el aula. Fundamentalmente, el trabajo consistía en la adaptación "digital" del tipo de tareas y procedimientos recogidos en la guía docente en la asignatura. Todo el material (podcast, presentación, enlaces, recursos, etc.) se recogen en un sitio web localizable desde el Campus Virtual de la Universidad de La Rioja.

b) Explicación de la actividad en el aula. El docente, en el aula, con el grupo de alumnas explicaba los objetivos, los procedimientos, los contenidos, la temporalización y los criterios de evaluación, utilizando para ello los materiales ya disponibles en la red.

c) Trabajo autónomo y colaborativo por parte de las alumnas. Disponían de entre una y tres semanas para desarrollar el trabajo propuesto (en función de la duración estimada de cada una). Este proceso se podía realizar de modo autónomo -es decir, cada alumna separada espacial y temporalmente del resto-, de modo colaborativo fuera del aula, y de modo colaborativo dentro del aula, utilizando las sesiones específicamente programadas para tal fin y contando con el apoyo y asesoramiento del docente.

d) Evaluación de los contenidos. Un día antes de la presentación en el aula, el docente realizaba la evaluación de los materiales utilizados y ubicados en la wiki (imágenes, videos, documentos, presentación, textos, etc.). La rúbrica y descripción de la evaluación se realizaba en el apartado "discusión" de la propia wiki.

e) Evaluación de la presentación. El día asignado para cada uno de los subgrupos se realizaba la presentación de la práctica por parte de las alumnas. Esta tarea implicaba utilizar como soporte los recursos generados en la wiki, justificando la razón de su selección, diseño y utilización. Al acabar la presentación (de entre 15 y 30 minutos), el docente volvía a incluir la evaluación dentro de la wiki. En este caso se evaluaban más los aspectos formales (lenguaje, fluidez, interés, dinámica, etc.) que los recursos mismos, que ya habían sido evaluados anteriormente.

\section{RESULTADOS}

Los resultados de esta experiencia se pueden valorar a través de las encuestas que las alumnas respondieron una vez terminado el trabajo propuesto en la asignatura y, concretamente, tras la realización de las tareas prácticas. Respondieron a la encuesta (realizada con un servidor de cuestionarios 2.0), 50 de las 68 alumnas matriculadas en la asignatura, lo que representa casi un $74 \%$. 


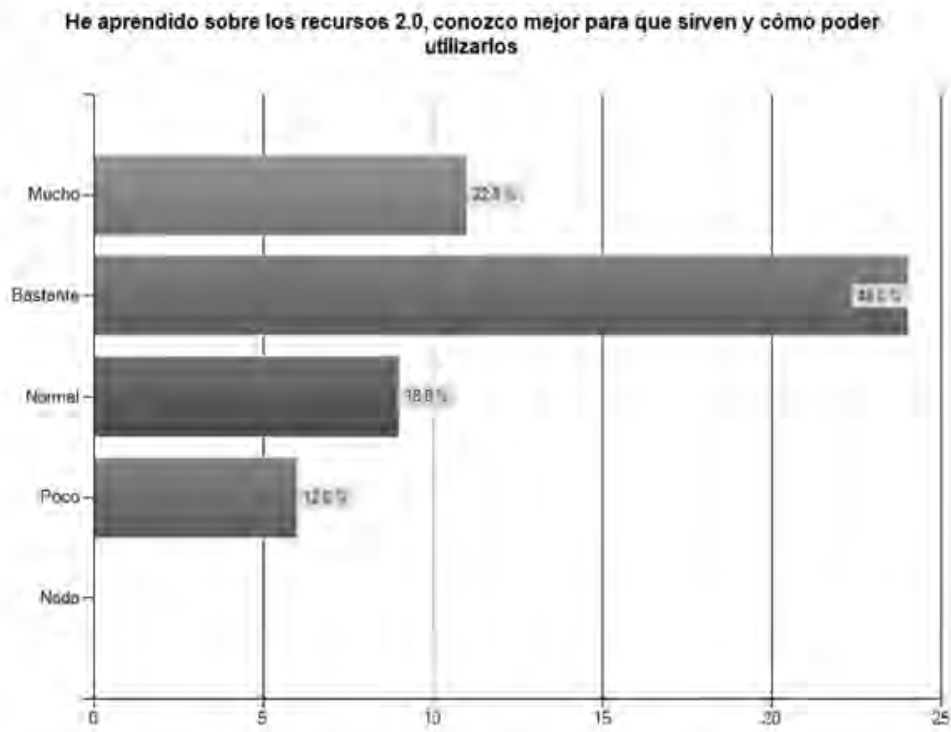

Figura 1

Un $70 \%$ de las alumnas opinan que han aprendido bastante o mucho sobre el manejo de las herramientas 2.0 seleccionadas para esta experiencia. Hay que tener en cuenta que se partía de un nivel bajo de conocimiento al respecto, aunque la progresión fue muy rápida.

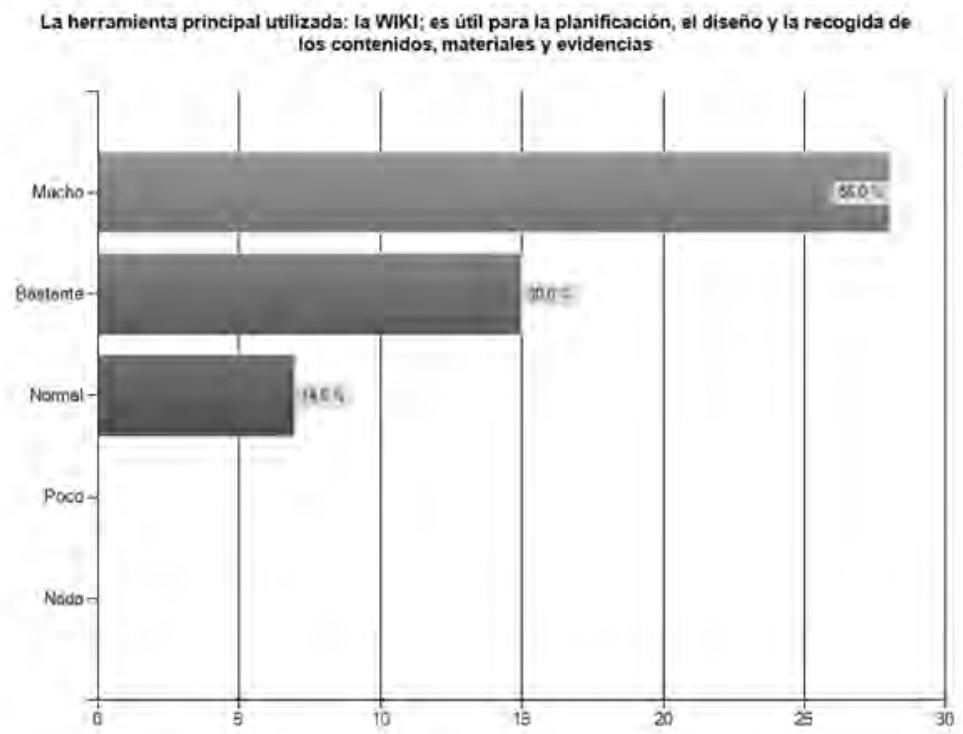

Figura 2 
En cuanto a la utilidad de la wiki, el porcentaje de estudiantes satisfechas se eleva al $86 \%$. El formato libre y la capacidad de editar contenidos parece que se perfila como una de las principales ventajas de esta herramienta.

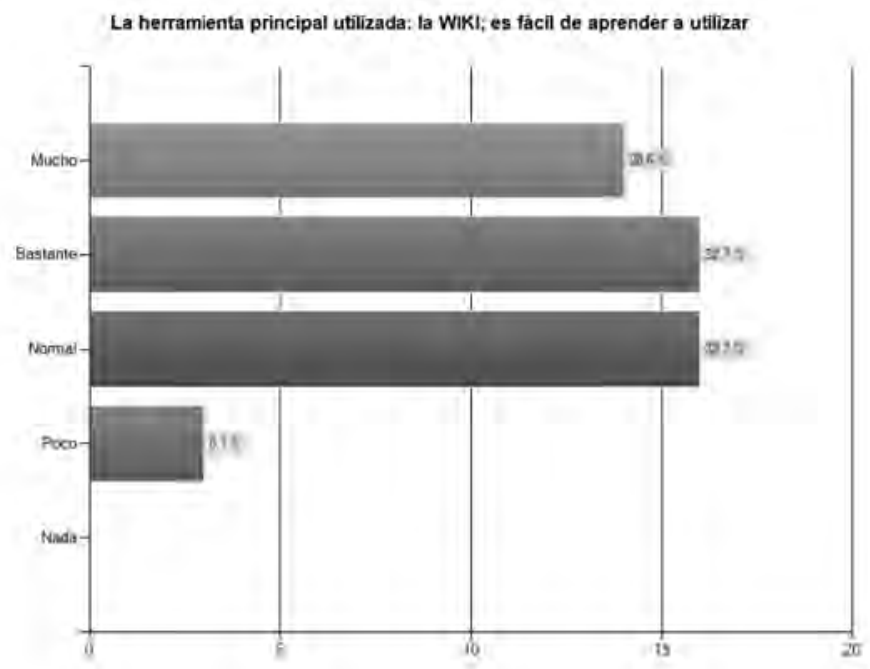

Figura 3

El resultado de esta pregunta confirma la inmediatez del aprendizaje de este tipo de utilidades. Como ya dijimos anteriormente, las alumnas adquirieron de forma muy rápida los rudimentos básicos de manejo de la wiki en un par de sesiones. Después, fue inmediato el inicio de las actividades y la producción de contenidos en este medio.

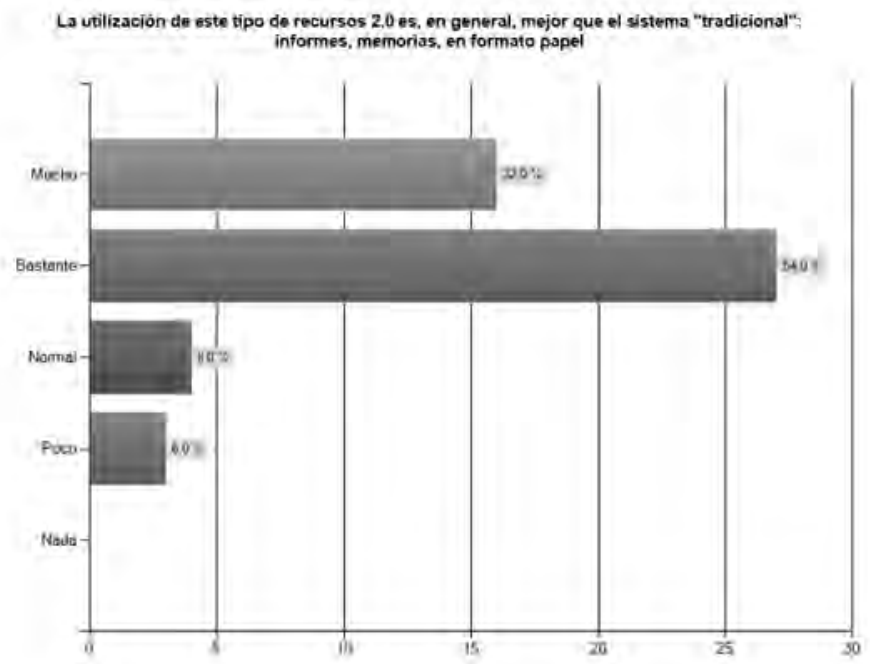

Figura 4 
Respecto a la comparación de este tipo de recursos con los tradicionales, el porcentaje de alumnas que lo prefieren llega al 86\%. Esto nos debe hacer reflexionar sobre las nuevas técnicas de trabajo que se pueden poner en práctica en la enseñanza universitaria y sobre las preferencias que manifiestan las nuevas generaciones de estudiantes.

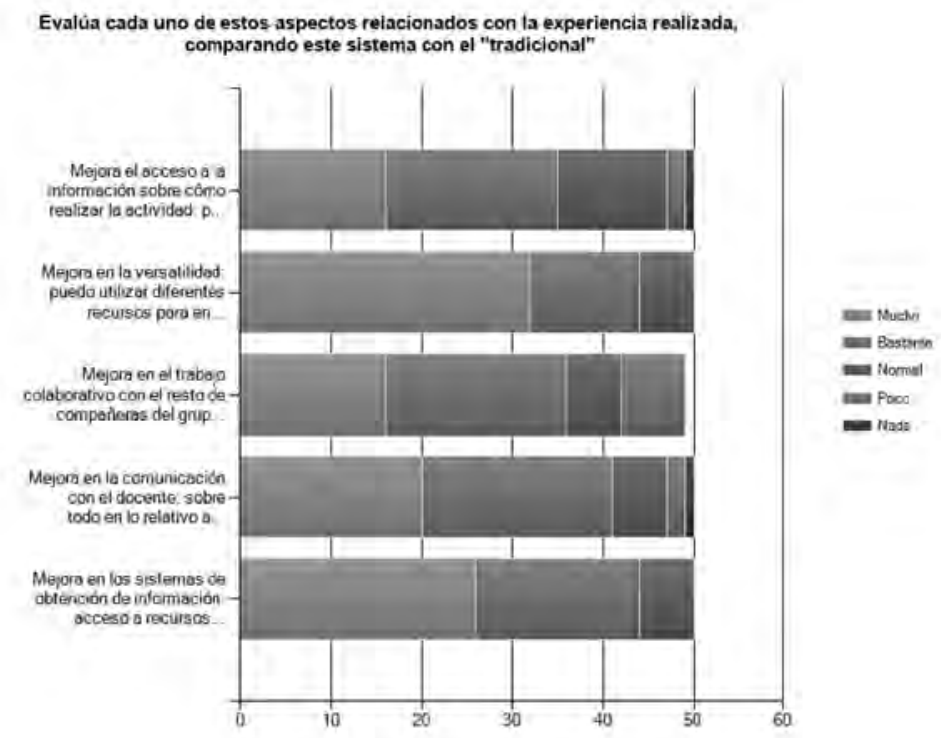

Figura 5

En la comparación con el sistema tradicional se puede observar que los ítems "Mejora en la versatilidad: puedo utilizar diferentes recursos para enriquecer mi trabajo (vídeos, presentaciones, imágenes, tablas...)" y "Mejora en los sistemas de obtención de información: acceso a recursos en internet, alojamiento de la información (vídeos, presentaciones)" son los que obtienen una mayor valoración por parte del alumnado. De este dato se puede deducir que es la forma de trabajo o los aspectos de tipo instrumental los que salen más reforzados del trabajo con herramientas 2.0. En un tercer lugar se valora la comunicación con el docente. Este aspecto adquiere importancia por el cambio que supone en el rol del profesor.

\section{CONCLUSIONES}

1. El uso de herramientas 2.0 en el ámbito universitario permite una nueva dinámica en el aprendizaje y facilita el diseño y el intercambio de información, conocimiento y recursos entre los miembros de los grupos y el docente.

2. Este tipo de aprendizaje promueve un cambio significativo tanto en el rol del profesorado y del alumnado como en los conceptos y los procesos relacionados con la selección y la presentación de los contenidos y los sistemas de evaluación y autoevaluación. 
3. El empleo de las TIC y, en concreto, de las herramientas 2.0 es manifiestamente preferido por las estudiantes respecto de otros sistemas tradicionales.

4. Las participantes proponen seguir con este tipo de metodología y recursos en el futuro, ampliando las materias y contenidos a trabajar con herramientas 2.0.

Se es consciente de las limitaciones del estudio que se presenta, fundamentalmente por el reducido tamaño de la muestra, pero aun así, una vez realizada la experiencia, nos lleva a plantear nuevos campos de estudio que amplíen y enriquezcan este tipo de líneas de investigación.

\section{REFERENCIAS BIBLIOGRÁFICAS}

BOEKAERTS, M.; PINTRICH, P. R. y ZEIDNER, M. (2000). Handbook of self-regulation. San Diego: Academic Press.

CANO, E. (2008). La evaluación por competencias en la Educación Superior. Profesorado. Revista de currículum y formación del profesorado, 12(3).

DE LA FUENTE, J. y JUSTICIA, F. (2003). Regulación de la enseñanza para la autorregulación del aprendizaje en la universidad. Aula Abierta, 82, 161-171.

ECHAZARRETA, C.; PRADOS, F.; POCH, J. y SOLER, J. (2009). La competencia "el trabajo colaborativo": Una oportunidad para incorporar las TIC en la didáctica universitaria. Descripción de la experiencia con la plataforma ACME (UdG). UOC Papers: Revista sobre la sociedad del conocimiento, 8.

GERARD, F. M. y BIEF (2008). Évaluer des competences. Guide pratique, Bruxelles: De Boeck.

MCDONALD, R.; BOUD, D.; FRANCIS, J. y GONCZI, A. (2000). Nuevas perspectivas sobre la evaluación. Boletín Cinterfor, 149, 41-72.

MORAL, M. E. D. y VILLALUSTRE, L. (2008). Las wikis vertebradoras del trabajo colaborativo universitario a través de WebQuest. RELATEC: Revista latinoamericana de tecnología educativa, 7(1), 73-83.

RIESCO, M. (2008). El enfoque por competencias en el EEES y sus implicaciones en la enseñanza y el aprendizaje. Tendencias Pedagógicas, 13, 79-105.

RODRÍGUEZ DIÉGUEZ, J. L. (2004). La programación de enseñanzas, el diseño y la programación como competencias del profesor. Archidona: Algibe.

SANTIAGO, R. y NAVARIDAS, F. (en prensa). La Web 2.0 en escena. Píxel-Bit. Revista de Medios y Educación. Publicación anticipada en línea en: http://sav. us.es/pixelbit.

TRUJILLO, J. M. e HINOJO, F. J. (2010). Apropiación de recursos y estrategias 2.0 para la innovación educativa en la docencia universitaria. Enseñanza \& Teaching: Revista interuniversitaria de didáctica, 28, 61-77. 